\title{
Multidimensionality of thinking in the context of creativity studies
}

\author{
Anastasiya K. Belolutskaya \\ Moscow City Teachers' Training University, Moscow, Russia \\ E-mail: anabel@eurekanet.ru
}

This article describes the theoretical difference between the flexibility and the multidimensionality of thinking. Multidimensionality is discussed as a characteristic of thinking that is necessary for exploration of the variability of structural transformations of problematic situations.

The objective of the study was to examine a number of theories concerning the correlative connection between the multidimensionality of thinking and other characteristics of creative, productive thinking: the flexibility of thinking; the formation of an operation of dialectical thinking such as "mediation"; the ability of a person to use a scheme as an abstraction for analysis of various specific content.

A total of 85 people participated in the study: they were 15 to 17 years old, students at a senior school in Kaliningradskaya oblast, winners of different stages of the all-Russian academic competition in physics, chemistry, and mathematics. All respondents had a high level of academic success and of general intelligence.

The following techniques were used in this study: (1) my technique for diagnostics of the multidimensionality of thinking; (2) my technique of "schemes and paintings," designed for diagnostics of the ability to relate abstract schemes and various specific content; (3) the Torrance Tests of Creative Thinking (verbal battery); (4) a diagnostic technique for dialectical thinking: "What can be simultaneous?"

All the hypotheses were confirmed.

Confirmation was received of the existence of a correlation connection; this finding counts in favor of the assumption that the parameters of thinking my colleagues and I were working with can in aggregate be considered an integral characteristic of human thinking. It allows us to distinguish significant features of a situation from secondary ones-that is, to see a substantial contradiction and to propose several options for its transformation.

Keywords: multidimensionality of thinking, dialectics, theoretical generalization, flexibility, transformation, intellectual creativity 


\section{Introduction}

The mechanisms and characteristics of creative thinking are the subject of studies by many major researchers both in Russia (Altshuller, 2007a, 2007b; Bayanova, 2012; Belolutskaya, 2011; Davydov, 1996; Elkonin, 1994; Galperin, 1966; Krasheninnikov, 2005; Leontiev, 1975; Lewin, 2001; Rubinstein, 1957; Spiridonov, 2000; Velichkovsky, 2006; Veraksa, 2009; Vygotsky, 1934/1999; Wertheimer, 1987) and abroad (De Bono, 2000; Dorner, 1997; Duncker, 1965; Gardner, 2007; Guilford, 1959; Lévy-Bruhl, 1994; Piaget, 1953/1994; Sternberg, 1959; Torrance,1962). Despite differences in approach, it is still possible to define some features that are considered fundamental by the majority of researchers. One of these features is, for instance, flexibility of thinking.

This notion became truly crucial within the creativity concept of Guilford (1959) and Torrance (1962), although many other scientists mentioned the necessity to "change position," "look from a different angle," "make up the most impossible and fantastic variants of a solution," "forget stereotypes," and so forth, while discussing the increase of the probability of a creative solution. Initially, "demonstration of flexibility of thinking" meant production of a maximum number of options regarding what to do with an object-for example, with a brick or a head of cabbage. Thus, the differences among those options must have been based on the diverse characteristics of that object. For example, a proposal to play football with a head of cabbage and also to throw it and break a glass window does not indicate flexibility because the same feature of the object was used-its ability to be thrown. But a proposal to play football and then to play cards by drawing suits and pictures on cabbage leavesindicates flexibility because, first, the head of cabbage was thrown and, second, it was taken to pieces. At a later stage this idea was elaborated in the design of diagnostic techniques. The following type of tasks began to be proposed: "Please ask as many questions about the picture as possible." The stimulus material could be, for example, a picture of a boy looking at his reflection in a pond (actually the content of the picture was of no significance). Suppose a respondent asked, "Why is the boy wearing shorts?" and then "What is the color of his hat?" Those answers do not reflect flexibility because both the questions concerned clothes. But if the "hat" question came first and then, for example, "Does he have any siblings?" one could say the answers reflect flexibility because the respondent pointed to different characteristics of the boy: he simultaneously could be wearing clothes and be a member of a family. Such an interpretation of creativity was the subject of just criticism by many local and foreign researchers because of its empiricism and lack of methodological elaboration of the qualitative distinctness of the mental structures forming the basis for intellectual action (Sternberg \& Grigorenko, 1997). The person completing the task (a) proposes "thumbing through" variants and (b) does not solve the problem (because the question set by this technique does not present a problem requiring a solution but rather some fantasizing concerning the stimulus material).

In turn we can particularize a description in a Torrance test and its interpretation to point out one specific feature crucial for further discussion: in order to demonstrate this kind of flexibility, respondents need to mentally pull apart an entire object into different features. Given that the essence of the object inevitably gets lost 
when a head of cabbage is used for football, it is not a head of cabbage anymore but a ball; in the card game, it turns into a kind of a notebook with pages that tear off. The object becomes dissociated in human thinking. The disintegration of the parts of the object either leads to making depthless decisions about possible transformations (that is, only separate nonsignificant elements become the subject of changes) or, vice versa, leads to the appearance of something new that probably features some similar external characteristics but is essentially different.

From my point of view, opportunities for qualitative transformation appear when the object is initially considered as a whole, so that it is not separate elements that become crucial but the principle of their holistic organization. Primacy of the whole over its elements is acknowledged by gestalt psychologists, from one side, and researchers working in the tideway of dialectical methodology, from another. One can find the following speculation in Arsenyev, Bibler, and Kedrov (1967, p. 210):

Creative thinking, founded on imagination, can be characterized as follows: the new always emerges as a whole, which later on forms its parts, deploying into a system. It looks as if thinking was "capturing" the whole before its elements, and this constitutes a typical feature of contensive [content-related] creativity.

Davydov (1996, p. 145) also emphasized that this characteristic of creative thinking remains almost unexplored in psychology, even though "when being developed ... imagination is an ability to 'see the whole prior to its parts.' And it is very important as a prerequisite for and one of the necessary conditions of the theoretical reproduction of reality. One can say that when imagination is considered from this perspective, it becomes one of the manifestations of theoretical thinking."

Thus, immersing the discussion about mechanisms of creative transformation in the context of the problem of the relation of the whole and its parts leads to the necessity of distinguishing ways of transforming objects, which is inherent in theoretical and empirical thinking.

When it comes to understanding the process of development in the context of theoretical and empirical generalization, let us cite Davydov (1996, p. 87) again:

Envisaging the development process constantly demands demonstration of some result through the process that led to it (already completed!) and [demonstration of] the process through the expected result (not accomplished yet!). This is the only way to understand and comprehend real interconnections of single-unit objects within concreteness. ... Mediations and transitions actually present this internal movement, whose form is necessity, generality, i.e., internal completeness and "purity." Such a reproduction can be performed by theoretical thinking only (all those "transitions and mediations" are in its element!), and its content (the specific type of connection of single units within the whole) cannot be restricted to any one sense.

Discussing the extent of absurdness that can be reached by empirical generalization, many authors have spoken of the possibility of comparing a raspberry bush not only to a blackberry bush but also to a turtle (Drobish, 1842). Lotse underlined that "cherries and meat can both be included in a group of red juicy bodies" (1874- 
$1879 / 1912$, p. 324). These examples were ironically devised by scientists, but if we remember the aforementioned head of cabbage, it will become clear that this kind of scheme works when an object gets included in different and very unreasonable contexts element-by-element.

So, let us highlight the conclusion that can be reached at this stage of the discourse: flexibility of thinking taken in the sense assigned to it by Torrance has an empirical character. On that level of transformations, where qualitative argument and development are needed, creative thinking is obliged to be theoretical.

We can transform a contradiction only through comprehension of the principle of the organization of (a) that whole in which the contradiction emerged and (b) that whole we want to receive as the result of the transformation. However, on the level of theoretical generalization, various vectors of transformation become possible: the "new that emerges as a whole" matches the initial structure; however, the number of new essences appearing because of those transformations can be unlimited.

I suggest using the concept of the multidimensionality of thinking as a characteristic that describes the variability of qualitative transformations on a theoretical level of generalization. Multidimensionality of thinking provides variability of the transformations of a substantial contradiction in a problematic situation.

Multidimensionality allows seeing the same object on the borderland of different structures. This, among other aspects, provides an opportunity to configure a situation in a certain fashion: while being included in structure $A$, an object may be a weak link, but, once moved to structure B, it becomes a key to resolving the problem. Multidimensional thinking is characterized by a specific level of creative transformation of a problematic situation: it allows solving the problem, building structural relations between two or more formerly independent constructions, and, by this means, projecting a metaconstruction featuring much greater development capacity than the initial constructions had.

As mentioned above, the studies conducted within the framework of dialectical methodology are of distinct significance for this research project. I consider the structural dialectical approach in psychology as developed by N. E. Veraksa $(2007,2009,2010)$ to be the most promising among all modern schools. Its major provisions are present in the works of Bayanova (2012), Belolutskaya (2011, 2013), Krasheninnikov (2005), Pashenko (2010), Rachkova (2010), I. B. Shiyan (2011), O. A. Shiyan (2008), A. N. Veraksa (2013), E. V. Vorobieva (2010), I. I. Vorobieva (2010).

Methodological elaboration of the qualitative distinctness and possible variants of dynamic structures in which transformation of contradictions can be developed - that is, operations of dialectical thinking - is the strong point of this approach. I consider the following operations to be of the most interest here: "change of alternative" and "dialectical mediation." The structural dialectical approach understands a change of alternative as a transition from one pair of oppositions forming the essence of an object to another (Krasheninnikov, 2005). Mediation is a solution implying the discovery of such an object or phenomenon where given oppositions can coexist simultaneously (Krasheninnikov, 2005). From my point of view, complex implementation of the mentioned operations is the main mechanism for demonstrating multidimensionality as a characteristic of creative thinking. 
These theoretical grounds became the basis of an empirical study whose goal was to verify the existence of correlative connections between such features of creative thinking as multidimensionality and flexibility; multidimensionality and dialecticalness of thinking; multidimensionality and the ability to use a scheme as an abstraction for analysis of specific content (which I consider one of the crucial features of theoretical thinking). Results of this study are presented below.

\section{Method}

\section{Hypotheses}

In this study I examined a number of theories concerning the correlative connection of multidimensionality of thinking and other characteristics of creative productive thinking as follows:

There is a significant positive connection between multidimensionality of thinking and flexibility of thinking.

There is a significant positive connection between multidimensionality of thinking and the form of an operation of dialectical thinking such as mediation.

There is a significant positive connection between the multidimensionality of thinking and the ability of a person to use a scheme as an abstraction for analysis of various specific content.

A key goal of this study was to clarify the characteristics of the connections among multidimensionality, flexibility, and the theoretical nature of thinking.

\section{Participants}

A total of 85 people participated in the study. They were 15 to 17 years old, students at a senior school in Kaliningradskaya oblast, and winners of different stages of the all-Russian academic competition in physics, chemistry, and mathematics. All respondents had a high level of academic success and of general intelligence.

\section{Methodological toolbox}

The following techniques were used in this study:

The author's technique of diagnostics for the multidimensionality of thinking (hereinafter referred as DMT)

The author's technique "schemes and paintings," which was designed for diagnostics of the ability to relate abstract schemes and various specific content

Torrance Tests of Creative Thinking (verbal battery) (Tunik, 1998)

A diagnostic technique for dialectical thinking: "What can be simultaneous?" (developed by N. E. Veraksa) (2007) 
In order to perform statistical analyses of the collected data, the Pearson moment-product correlation coefficient and the Spearman range correlation coefficient were used. They match the aim of testing statistical significance in order to verify the hypotheses and to clarify the characteristics of the connections between the pairs of variables. The sample of 85 people was sufficient for calculation of both coefficients.

\section{Objectives and description of techniques}

For the purposes of this study I developed a method dedicated to the diagnostics of multidimensionality of thinking (DMT). The method consists of describing a problematic situation to be resolved by the respondent. In addition, the respondent is given a list of external circumstances that are not initially related to the problem. The task is to build a semantic metaconstruction (or several metaconstructions) that can become a solution for the initial problem.

The description of the situation does not provide any hint about a "correct" way of solving the problem - that is, it is a problem, not a task. In order to transform an abstract situation of tension into a chain of specific steps, the respondent mentally projects variants of possible constructions that can vary in content significantly but have similar structure. This structure represents the outcome of mental transformation, where external factors not connected to the initial situation start to be considered as resources and turn into potential "points of growth," vectors of the development of the situation.

Here are the instructions given to the respondents.

Dear participants in the survey!

We are conducting a study of specific acts of creative thinking in children, teenagers, and adults. Please read attentively the tasks below and give the most detailed answers you can. Responses should be in a free format and in writing.

Thank you for your participation!

Once upon a time there was a very talented man. He was 30 or maybe 40 years old. Maybe he had a family, maybe not. Maybe he went to an office every day, or maybe he stayed at home most of the time. We're not familiar with all these details. But for many years he had been painting wonderful landscape scenes. Friends and acquaintances often told him that he could feel nature and transfer its beauty to the canvas like no one else. His whole house was decorated with paintings, and he gave many of his masterpieces to friends, as he loved to meet with them....

But one day he realized that painting was his mission and the basis of his life. However, it's not that easy to become a real painter! It is one thing to paint for pleasure as a hobby and another to grow professionally, establish a career, make money, and promote oneself...

What advice would you give to our protagonist, who has made a serious decision to make painting his profession?

For reference:

The action takes place nowadays. The city where this man lives is a big industrial administrative center. 
This morning he opened a newspaper and became aware of some of the latest city news, in particular:

(1) The level of unemployment increased 20\% compared with the previous year. The general level of the life of the population continues to decrease.

(2) Demonstrations of ecoactivists against air pollution in the city are becoming more and more aggressive. Yesterday they were picketing an oil refinery, police had to intervene; some demonstrators were injured, and some were detained.

(3) A bill before the city council proposes a ban on recreational hiking in forests because of frequent fires. It continues to be very hot.

(4) The three top projects in a competition of young scientists were the following:

- Technology that significantly lowers the cost of 3D printing. This techology can be used for domestic purposes and in the printing industry, and it is also possible to use it to print books with volumetric illustrations.

- Technology that reduces by almosttwo times the cost of running electric cars (cars working on electricity, not petrol).

- Technology that reduces the cost of diagnosing medical diseases by inserting into the body a scanning microrobot.

(5) Our protagonist was surprised to see a picture of a former classmate in the high-society news section. The article revealed that she had married a famous city businessman, quit her job, and started writing children's books under a pen name. Unfortunately she had recently given birth to an ill child. In the interview she claimed her intention to fight for his health by all means and, even more, to do her best to provide decent treatment for other children with the same diagnosis. A well-known doctor commented on this news and proposed reducing the concentration of heavy metals in the atmosphere as the best preventive measure against such diseases.

(6) The city football team easily won thenational championship with an amazing score, although the goal keeper claimed that he had decided to leave his profession because of his age.

(7) Inhabitants of big apartment blocks now have the right to make renovations in their entrance halls without informing city authorities.

(8) Volunteers collected within a week three trucks' worth of food and warm clothes for the victims of flooding in neighboring villages.

(9) A famous foreign band will visit the city as a part of their current tour.

(10) On the eve of mayoral elections the city budget for social expenses was increased, including money for the following items:

- Creation of tourism venues that would appeal to children

- Encouragement of children's artistic creativity

- More children's sport activities

- Projects that would increase the cultural level and patriotism of citizens

Please propose several options for further action by our protagonist. 
This problematic situation is related to professional mission and choice of a way in life. The situation is based on a possible transformation of the protagonist's painting as a hobby into painting as a profession, instead of simply changing his profession, for example, from driving to sales. Obviously, in such a situation the protagonist has to invent and undertake a number of projects because if he immediately leaves his job and starts to produce paintings for sale, he will have a high probability of failing. A change of professional direction, especially to such a creative occupation, is always fraught with many risks, both economic and personal. However, such factors as internal calling, the sensation of the correctness of the existential choice, and psychological comfort are important. A successful resolution in this case must (a) preserve the initial goal of becoming a professional painter and (b) transform the situation in such a way that external conditions become not an obstacle but a source of development.

The "news" gleaned by the protagonist is actually a set of factors that (a) are not related to his internal problem, (b) create a background that is either unfavorable or neutral for the protagonist, (c) have relevance for him in the sense that, for example, they are city, not international, events, $(\mathrm{d})$ cover various areas, being rather a patchwork than a system, so that the respondent has to construct connections. The current situation in the city is, certainly, fairly disadvantageous for a risky project such as replacing a stable job with creative profession: the level of life is decreasing while unemployment is increasing; there are many ecological problems and general tension.

The objective of this technique was to find out (a) to what extent the respondent can transform unfavorable conditions into resources while preserving the initial goal, not another one, and (b) how diverse the proposed project solutions are-that is, how many independent lines of development of the situation a respondent can construct based on the different factors listed above or, perhaps, on other factofs suggested by the respondent.

Each solution of this problem that was based on different factors gained 1 point. Respondents did not get any points if they (a) described a way of "escaping the problem" (continue painting as a hobby, move to another city where "rich and wealthy people live"), (b) described a successful ending without revealing how it could happen ("protagonist left his work, started selling his paintings, and lived happily and harmoniously ever after"), (c) proposed solutions that were based on the given factors but did not resolve the initial problem or replace it with another one. For example, "the protagonist will paint banners for ecoactivists and together they will improve air quality in the city" or "he will paint good pictures for the ill kid of his classmate and the baby will get better" or "he sells all his paintings to the classmate's husband and gives that money to flood victims."

Thus, the minimum number of points received by a respondent was 0 , while the maximum score was theoretically unlimited because respondents were given an open question. The highest score gained by one respondent in this study was 8 .

This is an example of an answer that got 8 points (R. L., 15). "Our protagonist could start by organizing workshops for children interested in creative arts (1 point); he could also paint the house entrances ( 1 point). That way he would be noticed by the local government, and he might be mentioned in the newspaper. Then he could get in touch with his classmate and the ecoactivists. He could start 
painting 'before' and 'after' landscape scenes, showing how nature looked before and how it will look later if the factory is not closed down (1 point). His classmate is highly interested in shutting the factory because of her child's disease, so she could finance the painter and his assistance for ecoactivists (1 point). When the factory finally closes down, the situation with tourism will improve, so visitors coming to the city will attend his exhibitions and buy his works; he will be a local celebrity by this time (1 point). He could also hold an exhibition and an auction to help the victims of the flood. It's not a way to make money but is good marketing (1 point). He could promote himself by illustrating books and propose making paintings for $3 \mathrm{D}$ printing to the guys who won the grant (1 point); later he could use this work for his classmate's books. At the same time, he could make nice T-shirts for the concert of the foreign band or work as a stage decorator for them (1 point). Thus his 'all-round ad campaign' would be complete, and after that it's just a matter of doing the "paperwork."

Notice that this respondent constructed solutions for professional promotion of the painter based on various factors. The respondent did not just fantasize about a trouble-free future or, conversely, about a gloomy future for the protagonist. The respondent's solutions were instead created through the transformation of neutral or negative conditions into conditions for development of the situation.

For comparison, here is an example of an answer that was not worth any points (G.O.A., 16). "I think that the painter has to earn his livelihood through his art in any case. If he works this way he will feel pleasure in doing his job. In a few years he will be able to start up his gallery and so make money." This answer is not grounded in external factors and proposes no steps for development of the project. In contrast, the next example, which also received no points, does mention external factors: "The protagonist should wake up, have his breakfast, think it over, and realize that no one needs him or his paintings in that place. It is a depressed industrial city with bad ecological conditions and a low level of life. So he should go to work as an accountant or slash his wrists" (M.B., 16). But this respondent made no attempt to turn these factors into something positive and instead perceived them as threats.

The technique known as "schemes and paintings" was developed and tested in thesis research (Belolutskaya, 2011) conducted at Moscow State Pedagogical University (faculty of psychology and education) and Moscow school \#1716; there were 104 respondents in total. The tools for this method are a blank sheet for answers and an album with stimulus material. The stimulus material consists of (a) a page listing 5 schemes of different actions of dialectical thinking described in the works of N. E. Veraksa (2009): transformation, mediation, integration, seriation, termination (in order to make the scheme comprehensible to the respondents, its elements are presented as squares of black, white, and gray, and arrows indicate opposition and sequence), and (b) 6 sheets with small reproductions of paintings by famous artists (12 pieces): M. C. Escher's Bird Fish, V. Serov's Abduction of Europe, M. C. Escher's Drawing Hands, Leonardo da Vinci's Last Supper, M. Vrubel's Swan Princess, S. Dali's Three Sphinxes of Bikini, V. Vasnetsov's Sirin and Alkonost, the Birds of Joy and Sorrow, Raphael's Garvagh Madonna, M. Vrubel's Demon Seated, V. Vasnetsov's Alenushka, V. Vereshchagin's Apotheosis of War, Leonardo da Vinci's Vitruvian Man. Here are the instructions: 


\section{Dear participants in the survey!}

We are conducting research on specific acts of creative thinking in children and adults and would appreciate your collaboration.

You will find 5 schemes on page 2 and on pages 3-8 paintings by famous artists are reproduced (light copies). Some schemes and paintings express the same idea, or one scheme can match several paintings. Please relate schemes and paintings and provide explanations for why you have chosen those and not others. Try to explain each case with a maximum of details. If you think that some schemes do not match any paintings, please explain your opinion.

Write your answers on the blank sheet.

Do not rush, and please remember that there are no correct or incorrect answers.

The technique schemes and paintings" was designed to (a) reveal the ability of a person to use a scheme as an abstract principle of the organization of a whole and (b) record the variety of concrete content that a respondent could "insert" into a scheme. The ability to use a scheme as an abstract explanatory principle for the analysis of content is one of the signs of developed dialectical thinking, which is, as mentioned above, a basis for the presentation of multidimensionality.

The stimulus material was selected on the basis of the following criteria:

1) Schemes of dialectical mental actions are a graphic representation of dynamic and developing structures, not formal, static ones. The ability to analyze some content using such schemes is indicative of the multidimensionality of thinking, which, in turn, appears in the moment of transformation, the moment of the mental restructuring of a problematic situation.

2) Paintings of outstanding artists are rich material that, on the one hand, gives ground for various semantic interpretations but, on the other hand, is normally clearly structured in order to report the artist's ideas and conceptions. We chose two types of paintings for our stimulus material: (a) those with both visually presented two-sidedness (Escher's gravure with birds and fish, the Swan Princess, Sirin and Alkonost, the Abduction of Europe) and cyclicity (Escher's hands drawing themselves, Leonardo da Vinci's drawing Vitruvian Man); (b) those depicting one protagonist or object (Demon Seated, Alenushka, Apotheosis of War).

On the one hand, the paintings in the first group facilitate the task for respondents (lead them to see what can be represented by black and white squares in a scheme), but, on the other hand, they are a trap because they can provoke various empirical variants ("the arrows go in a circle in the scheme and Vitruvian Man is also located in a circle").

The paintings in the second group seem to be more complicated for analysis through binary organized schemes, but they evoke deeper content-related interpretations normally related to the internal conflict of the protagonists. 
The following interpretation criteria were used during data processing:

- How is the essential (abstract) understanding of the scheme as a means of analysis demonstrated by the respondents? Is it clear from their explanations that they see a system of relations "behind" black and white squares and arrows without adherence to specific geometrical form or color range?

- Can the respondents apply the scheme to the content of different paintings as an explanatory principle?

To simplify the processing of results, we developed the following system of allocation and calculation of points.

Respondents received 0 points if:

- Their explanations for the choice of paintings had nothing to do with the scheme. Either they did not answer directly-"It seems to me that..."-or their explanation was based on their emotional perception of the paintings- "I like these paintings, that is why I choose them."

- They matched a scheme and a painting because of random external similarity: "Here are two squares and there are two dolphins" or "the gray, white, and black squares make a triangle and in Raphael's picture the Madonna and two babies form a triangle too." Such answers failed to meet the requirement set in the instructions: "to express the idea of the scheme through the painting."

- In their interpretation of a scheme they did not specify the content: they confined themselves to such explanations as "both in the picture and in the scheme all elements are interconnected" or "the gray square affects the two below, and Christ influences all the people sitting at the table."

All these explanations are typical of empirical thinking.

Respondents received 1 point for every solution in which (a) the scheme was understood abstractly as a consistent principle of the organization of specific content, or (b) they could discover a meaningful system of relations of oppositions, transformations of one opposition into another, or the development of cyclicity behind the graphic elements. Solutions of this kind reflect theoretical thinking. Notably, if a respondent claimed that "scheme 1 reflects oppositions and therefore matches paintings 1,3,10 because good and evil are opposed there," such a judgment got 1 point despite several pictures being mentioned. In this case the respondent filled the scheme with only one content-related meaning-"good is opposite to evil." But if the respondent said that "scheme 1 reflected oppositions, therefore it matches paintings 1,3,10 because good and evil, beauty and ugliness, life and death were opposed there," that answer received 3 points, as the scheme was filled with diverse content.

Therefore, the minimum number of points received by a respondent was 0 , while the maximum score was theoretically unlimited. The highest score gained by one respondent in this study was 5 . 
Here are examples of answers that received points:

- The idea of scheme 2 (mediation) is expressed in painting 7 (Vasnetsov, Sirin and Alkonost, the Birds of Joy and Sorrow) because both Sirin and Alkonost are present there, opposing each other (they are personifications of joy and sorrow), and their song is the gray square because it unites the one and the other.

- The idea of scheme 4 (conversion) is expressed in painting 1 (Escher, Bird Fish) because the gray square is a person who has a choice-to fly up to the sky as a bird or to dive into the darkness [of the sea] as a fish.

- The idea of scheme 3 (seriation) is expressed in painting 1 (Escher, Bird Fish) because it shows the transition from one opposition to another (from a bird to a fish), just as the scheme does.

- The idea of scheme 3 (seriation) is expressed in painting 1 (Escher, Bird Fish) because it shows a gradual transition from catch (fish) to hunter (bird).

- The idea of scheme 3 (seriation) is expressed in painting 1 (Escher, Bird Fish) because one can imagine that the evolution of life on Earth was reproduced there.

- The idea of scheme 4 (conversion) is expressed in painting 4 (Last Supper) because the scheme represents the choice between good and evil made by Judas when he passed to the "dark side."

- The idea of scheme 5 (double mediation) is expressed in painting 3 (Escher, Drawing Hands) because the scheme represents various phases of cyclicity that are also reflected in the picture-the hands are drawing each other.

- The idea of scheme 3 (seriation) is expressed in painting 5 (Vrubel, Swan Princess) because it shows the transition from one state into another-the girl is turning into a bird.

- The idea of scheme 3 (seriation) is expressed in painting 2 (Serov, Abduction of Europe) and painting 11 (Vereshchagin, The Apotheosis of War) because in painting 2 the ox is taking the girl from the world of good to the world of evil (a smooth transition between oppositions), and in painting 11 everything started with a small conflict but resulted in a lot of blood, death, and devastation.

- The idea of scheme 1 (transformation) is expressed in paintings 3 (Escher, Drawing Hands), 7 (Vasnetsov, Sirin and Alkonost), 11 (Vereshchagin, Apotheosis of War), and 5 (Vrubel, Swan Princess) because all of them contain oppositions that conflict with each other but also transition into each other: real and drawn hands, joy and sorrow, life and death, a girl and a bird.

Thus, the schemes were interpreted by these respondents as an abstract principle by means of which it's possible to organize various specific kinds of content.

For comparison, here are answers that did not receive any points:

- The idea of scheme 1 is expressed by painting 1 because the scheme has only two colors, same as the painting. 
- The idea of scheme 3 is expressed by paintings $3,8,12$ because they also have a gradual transition of colors.

- The idea of scheme 5 is expressed by paintings 3,6 because the painter has depicted several similar people interacting with each other.

- The idea of scheme 5 is expressed by painting 12 because Vitruvian man looks like Zeus and there is an arrow looking like lightning in the scheme.

- The idea of scheme 4 is expressed by painting 8 because two babies are reaching out for mother, and their hands look like arrows.

- The idea of scheme 1 is expressed by painting 3 because it shows the interaction of objects depending on each other.

Such answers indicate that the respondent perceives a scheme not like an abstraction but empirically, as a drawing that requires another drawing by analogy.

The technique "What can be simultaneous?" was explicitly described by Krasheninnikov (2005). It is focused on diagnostics of an action of dialectical thinking such as mediation. Respondents name objects that could be simultaneously black and white, alive and not alive, big and small, light and heavy, fast and slow. One can call their answers productive solutions when the instructions are met completelythat is, when the object named can really be characterized as having opposite features (gray color, a person in anabiosis, yoga in deep meditation)

To measure flexibility of thinking the verbal battery of the Torrance Tests of Creative Thinking was used, but results were calculated only for the parameter flexibility and not for elaboration, fluency, and originality. From my point of view, the verbal battery is an "empirical analog" of the multidimensionality of thinking: it makes correlation analysis reasonable.

\section{Results}

The Pearson moment-product correlation coefficient and the Spearman method were used for mathematical processing of the data. To confirm the hypotheses the correlation coefficients were calculated between the following parameters:

1) Flexibility of thinking (Torrance test) and multidimensionality of thinking (DMT technique); $r x y=0.391$ when $n=85$, the coefficient was significant with the error probability less than $1 \%$.

2) Dialectical thinking (technique "What can be simultaneous?") and multidimensionality of thinking (DMT technique); $r x y=0.210$ when $n=85$, the coefficient was nonsignificant; $r x y=0.261$, the coefficient was significant with the error probability less than $1 \%$. The first coefficient was calculated using the Pearson moment-product correlation coefficient; the second was calculated using the Spearman method.

3) Multidimensionality of thinking (DMT technique) and the ability to use a scheme as an explanatory principle of specific content ("schemes and paintings" technique); $r x y=0.271$ when $n=85$, the coefficient was significant with the error probability less than $1 \%$. 
Consequently, we can state that the hypotheses were empirically confirmed. For the first and third hypotheses the correlation coefficients were significant when calculated by both the Pearson and the Spearman methods. For the second hypothesis, a significant correlation coefficient was received only by means of the Spearman method.

Confirmation of the existence of the correlations confirms the assumption that the parameters of thinking studied can in aggregate be considered an integral characteristic of human thinking. This characteristic allows us to distinguish significant features of a situation from secondary features - that is, to see a substantial contradiction and to propose several options for its transformation.

\section{Discussion}

When analyzing the significant correlations, one should keep in mind the following points.

First, I consider the discovery of a positive connection between the multidimensionality of thinking and the ability to use a scheme as an abstraction for analysis of specific content absolutely vital. I regard this correlation as an argument in favor of the idea that multidimensionality is a characteristic of theoretical, not empirical, thinking (Davydov, 1996). This statement is subject to further experimental examination, but already one can predict that people who master a scheme as an analytical means will be successful in completing tasks that require keeping hold of a problem, in taking many diverse factors into account, and in building constructions of possible transformations of problematic situations. Exploration of the specifics of the connection of the factors mentioned is a possible line of further productive studies on thinking. These data are of practical value in general and professional education as well as in courses dedicated to the development of productive thinking.

Second, the appearance of the concept of the multidimensionality of thinking became possible only in the tideway of the structural dialectical approach in psychology. Dynamic structures, processes of development, and transformations are the subjects of studies within this approach. If people can build a metaconstruction with a development capacity higher than that of the one they initially had, they have a blueprint of the structure of qualitative transformation. A qualitative transformation is any development phase deployed in accordance with dialectical structure. From this perspective the discovery of a connection between the multidimensionality of thinking and the use of dialectical mediation is quite explicable: in order to see potential points of growth in unfavorable factors, one needs to execute the action of "changing the alternative", and in order to execute a project decision, one needs the action of mediation.

Third, the direct connection between the multidimensionality and the flexibility of thinking is logical and expected. However, multidimensionality is a more complex feature than flexibility. We can anticipate that increasing the level of multidimensionality will cause an increase in flexibility, but the reverse is highly unlikely: even if one trains flexibility of thinking, it will not transform into multidimensionality. 
Thus, this study succeeded in producing empirical evidence confirming the connection of such important characteristics of thinking as multidimensionality, dialecticalness, theoreticalness, and flexibility. The character and qualitative specifications of those connections are a subject for further experimental research.

\section{Conclusions}

This study produced empirical evidence confirming the direct correlative connection between the multidimensionality of thinking and the following features of creative, productive thinking: flexibility, dialecticalness, and the ability to use a scheme as an abstract explanatory principle for specific content.

Examining these research results and those of previous studies reveals that they follow the logic not only of Russian authors (for example, Belolutskaya, 2011) but also of foreign scientists. For example, Paletz and Peng (2009) have also explored the connections among creativity, dialectical thinking, and the ability to discover a problem. Originality and relevance were taken as criteria of creativity when dialectical thinking was measured by means of the Spencer-Rogers Dialectical Self Scale. Discussing their results, the authors underline the highest importance of studying the connection between creativity and dialectical thinking. In the framework of cross-cultural research they revealed a positive connection between an index of the originality of solutions and dialectical thinking in situations with a high extent of contrariety. However, at the same time they discovered the huge role of the factor of cultural belonging. The connection of creativity and dialecticalness of thinking is much more complicated than is commonly thought. For instance, this study revealed a positive correlation only for a sample of Americans of European origin and only with one parameter of creativity.

Yang, Wan, and Chiou (2010) also examined the connection of all the parameters of creativity and dialectical mental attitudes but used different diagnostic techniques-the Social Paradigm Belief Inventory (Kramer, 1992) and the Divergent Thinking Test (Lin \& Wang, 1994).The measurements demonstrated significant positive connections between dialecticalness and creativity on all parameters in a sample of Taiwanese citizens.

Many Russian and Western researchers regard dialectical thinking as a determining factor in higher intellectual creativity. Furthermore, some authors view dialectical thinking as a concept that may replace creativity. In particular, Arlin (2011, p. 386) have stated:

New measures and assessments of postformal and dialectical thinking have contributed to the progress made in the study of advanced forms of adult thinking. There is no parallel development of ways to assess mature creative thinking. Even the most recent assessments rely heavily on Guilford's "structure of the intellect" model of 1967 and Torrance's translation of a subset of these factors into a set of divergent thinking tasks. What is needed to propel this research forward are well developed postformal measures of creativity. Paletz and Peng have recently taken a step in this direction.

The usefulness of this study lies in the further theoretical and experimental development of the notion of multidimensionality of thinking. From my point of view 
it is a concept that can allow serious advancement in the exploration of mechanisms of intellectual creativity through the integration of strengths of the conceptn of creativity and the structural dialectical approach. My colleagues and I are going to continue working on diagnostic techniques focused on measurement of the multidimensionality of thinking. This work, in turn, will contribute to the construction of an experiment for establishing the connection of multidimensionality and other psychic attributes, particularly the ability to resolve problematic situations of various types with a strategy of projection and transformation.

\section{Acknowledgements}

I am grateful to Sergey Gomon, the head of the Center for the development of gifted children (Kaliningrad region) for his support in organization of the research.

\section{References}

Altshuller, G. S. (2007a). Naiti ideu [Find an idea]. Moscow: Labirint.

Altshuller, G. S. (2007b). Tvorchestvo kak tochnaya nauka [Creativity as exact science]. Moscow: Labirint.

Arsenyev, A. S., Bibler, V. S., \& Kedrov, B. M. (1967). Analiz razvivaushegosia ponitia [Analysis of concept development]. Moscow: Labirint.

Bayanova, L. F. (2012). K postanovke problemi subiekta kulturi v psihologii. [Toward a definition of the problem of the subject of culture in psychology]. Philology and Culture, 3, 294-298.

Belolutskaya, A. K. (2011). Razvitie dialekticheskoi strategii operirovania protivipolojnostiami u detei i vzroslih [Development of a dialectical strategy of mental handling with oppositions of children and adults]. Educational Journal of Bashkortostan, 2, 50-58.

Belolutskaya, A. K. (2013). Strukturnaia gibkost mishlenia v kontekste dialekticheskoi psihilogii. [Structural flexibility of thinking in the context of dialectical psychology]. Philology and Culture, 3, 290-298.

Davydov, V. V. (1996). Teoria razvivaushego obuchenia [Theory of the development of education]. Moscow: Progress.

De Bono, E. (2000). Lateral thinking. Moscow: Labirint.

Dorner, D. (1997). The logic of failure: Recognizing and avoiding error in complex situations. Moscow: Smysl.

Drobish, M. W. (1842). Empirische Psychologie nach naturwissenschaftlicher Methode [Empirical psychology by scientific method]. Leipzig: Voss.

Duncker, K. (1965). A qualitative (experimental and theoretical) study of productive thinking (solving of comprehensible problems). In Psilhologiya myshleniya [Psychology of thinking]. A.M. Matyushkin (Ed.). (pp. 21-85). Moscow: Progress. (Original work published 1926)

Elkonin, B. D. (1994). Introduction to developmental psychology (within the tradition of the cultural historical theory by L.S. Vygotsky). Moscow: Smysl.

Galperin, P. Y. (1966). Metod srezov i metod poetapnogo formirovania v issledovaniiah detskogo mishlenia [The cutoff method and the method of phased formation in child-thinking studies]. Voprosi psihologii [Issues in psychology], 4, 55-70.

Gardner, G. (2007). The structure of reason: The theory of multiple intelligence. Moscow: Whilliams.

Guilford, J. P. (1959). Three faces of intellect. American Psychologist, 14,132-156. doi: 10.1037/ h0046827 
Kramer, D. A., Kahlbaugh, P. E., \& Goldston, R. B. (1992). A measure of paradigm beliefs about the social world. Journal of Gerontology, 47, 180-189. doi: 10.1093/geronj/47.3.P180

Krasheninnikov, E. E. (2005). Dialectical psychology. Ufa, Russia: BGPU.

Leontiev, A. N. (1975). Activity. Consciousness. Personality. Moscow: Politizdat.

Lévy-Bruhl, L. (1994). Primitive mentality. Moscow: Progress.

Lewin, K. (2001). Transition from the Aristotelian to the Galilean way of thinking in biology and psychology. In Dynamic psychology. Selected works. Moscow: Smysl.

Lin, C., \& Wang, M. (1994). The creativity assessment packet. Taipei, Taiwan: Psychological Publ.

Lotze, H. (1912). System der Philosophie [System of philosophy]. Leipzig: Logik.

Paletz, S., \& Peng, K. (2009). Problem finding and contradiction: Examining the relationship between naive dialectical thinking, ethnicity, and creativity. Creativity Research Journal, 21 (2-3), 139-151. doi: 10.1080/10400410902858683

Pashenko, A. K. (2010). Razvitie normativnogo povedenia mladshih shkolnikov [The development of normative behavior in junior school students] (Author's abstract for doctoral dissertation). Moscow City University of Psychology and Education, Moscow.

Piaget, J. (1994). Logic and psychology. In Izbrannie psihologicheskie trudi [Selected works on psychology]. Moscow: Mejdunarodnaya pedagogicheskaya akademia (Original work published 1957).

Rachkova, E. V. (2010). Structurno-dialecticheski podhod k obucheniu studentov. [The structural dialectical approach to the education of students]. Vestnik Moskovskogo Gorodskogo Pedagogicheskogo Universiteta [Bulletin of Moscow City Pedagogical University. Series: Pedagogy and Psychology], 2, 17-26.

Rubinstein, S. L. (1957). Existence and consciousness. Moscow: Smysl.

Shiyan, I. B. (2011). Strukturno dialkticheski podhod v psihologii i kulturno-istoricheskaia teoria Lva Vigotskogo. [Structural dialectical developmental psychology and cultural historical theory by L. S. Vygotsky]. Vestnik Moskovskogo Gorodskogo Pedagogicheskogo Universiteta [Bulletin of Moscow City Pedagogical University. Series: Pedagogy and Psychology], 1, 34-43.

Shiyan, O. A. (2008). Razvivaushee obrazovanie v vuze [Developing education in universities: The dialectical structure of courses as a condition forstudents' development]. Psyhologicheskaya nauka i obrazovanie [Psychological science and education], 2, 6-8.

Spiridonov, V. F. (2000). Zakonomernosti ontogeneticheskogo razvitia produktivnogo mishlenia: [Objective laws of the ontogenetic development of productive thinking]. In Evrisitiki tvorheskogo mishlenia [Heuristics of creative thinking ]. Moscow: Russian State University for the Humanities.

Sternberg, R. J. (1959). Investing in creativity. American Psychologist, 7, 34-45.

Sternberg, R. J., \& Grigorenko, E. (1997) . Guilford's intelligence model: A structure without a basement. In D. B. Bogoyavlenskaya (Ed.), Major modern concepts of creativity and giftedness. Moscow: Molodaya gvardia.

Torrance, E. P. (1962). Guiding creative talent. New York: Prentice Hall. doi: 10.1037/13134-000

Tunik (1998). Diagnostika kreativnosti. Test E. Torrensa. Metodicheskoye rukovodstvo [Creativity assessment. E. Torrance's test. Handbook]. Saint Petersburg: IMATON.

Velichkovsky, B. M. (2006). Kognitivnaya nauka. Osnovi psihologii poznania. [Cognitive science: The basics of cognitive psychology]. Moscow: Academy.

Veraksa, A. N. (2013). Symbol as cognitive tool of mental activity. Psychology in Russia: State of the Art, 6(1), 57-65. doi: 10.11621/pir.2013.0105

Veraksa, N. E. (2007). Pensamiento dialectico y creatividad [Dialectical thinking and creativity]. Revista de Psicologia General, 5(11), 7-14. doi: 10.11621/pir.2010.0011 
Veraksa, N. E. (2009). Structure and content of dialectical thinking. Moscow: Faculties of Psychology and Education, Moscow State University.

Veraksa, N. E. (2010). Structural approach to dialectic cognition. Psychology in Russia: State of the Art, 3, 227-239.

Vorobieva, E. V. (2010) Osobennost simvolicheskih predstavleni mladshih shkolnikov ob odnoklassnikah [Specifics of symbolic representations by junior school students of their classmates] (Author's abstract for doctoral dissertation). Moscow City University of Psychology and Education, Moscow.

Vorobieva, I. I. (2010). Sviaz referentnisti i urovnia razvitia dialecticheskogo mishlenia u studentov [Connection of references and the level of development of dialectical thinking of students] (Author's abstract for doctoral dissertation). Moscow City University of Psychology and Education, Moscow.

Vygotsky, L. S. (1999). Mishlenie i rech [Thinking and speech]. Moscow: Labirint.

Wertheimer, M. (1987). Productive thinking. Moscow: Progress.

Yan, B., \& Arlin, P. (2011). Dialectical thinking: Further implications for creative thinking. In M.A. Runco \& S. R. Pritzker (Eds.), Encyclopedia of Creativity, 2nd ed. (pp. 547-552). Waltham, MA: Academic Press-Elsevier.

Yang, Ch., Wan, Ch., \& Chiou, W. (2010). Dialectical thinking and creativity among young adults: A postformal operations perspective. Psychological Reports, 106(1), 1-14. doi: 10.2466/PR0.106.1.79-92

Original manuscript received August 26, 2014

Revised manuscript accepted January 13, 2015

First published online March 31, 2015 